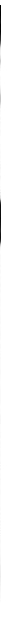

\title{
O ENSINO DE FILOSOFIA PENSADO À LUZ DE ALGUMAS QUESTÕES DA FILOSOFIA DA CIÊNCIA
}

\section{THE TEACHING PHILOSOPHY THOUGHT TROUGH SOME PHILOSOPHY OF SCIENCE ISSUES}

Tiago Luís Teixeira Oliveira ${ }^{1}$

Resumo: $O$ presente artigo traça alguns paralelos entre o ensino de filosofia e o ensino de ciências a partir de problemas amplamente discutidos por filósofos da ciência, especificamente o problema da demarcação e o problema do método. Sugerimos algumas pistas de reflexão sobre o ensino de filosofia para que este, no lugar de copiar um modelo inadequado e dogmático de ensino de ciências, possa instigar o espírito crítico e investigativo, também presente na atividade científica.

Palavras chaves: ensino de filosofia, problema da demarcação, problema do método.

Abstract: The present article draws some parallels between philosophy teaching and science teaching starting from problems widely discussed by philosophers of science, specifically the demarcation problem and the problem of method. We suggest some clues for reflection on philosophy teaching providing that, instead of copying an inadequate and dogmatic model of science teaching, it could instigate the critical and investigative spirit, also present in actual scientific practice.

Keywords: philosophy teaching, demarcation problem, problem of method.

\footnotetext{
1 Doutor em filosofia pela UFMG. Professor do Departamento de Filosofia do Colégio Pedro II. Email: tiagolvis@ymail.com.

Revista Digital de Ensino de Filosofia - Santa Maria - vol.3. n. 1 - jan./jun. 2017.
} 


\section{Introdução}

A reflexão sobre o ensino de filosofia não é algo recente na literatura. Os cursos de licenciatura no Brasil oferecem em sua grade disciplinas didáticas como a prática de ensino e disciplinas teóricas como filosofia da educação de modo que tais disciplinas ajudam a entender o ensino de filosofia como questão filosófica. Neste artigo não me proponho a refazer essa trajetória ou mesmo criticá-la. Pretendo tematizar o ensino de filosofia a partir de um olhar de quem estuda filosoficamente a ciência, algo como uma alternativa à tematização já oferecida. Existem alguns problemas amplamente discutidos por filósofos da ciência que poderiam ajudar a pensar o modo como a disciplina filosofia é lecionada em cursos superiores e, sobretudo, no ensino médio. A filosofia da ciência lida com certas questões fundamentais que permeiam a tentativa de definir o que é ciência em contraste com outros saberes (problema da demarcação), a tentativa de discussão sobre os métodos de investigação da ciência e se tais métodos garantem mais ou menos a alegação de conhecimento (problema do método), a questão de saber se há e, nesse caso, como ocorre progresso científico (o problema do progresso) e ainda se a ciência é capaz ou não de informar como o mundo é em seus aspectos observáveis e inobserváveis (o debate entre realismo e antirrealismo científico). Deparar com tais problemas e refletir seriamente sobre eles traz como consequência uma crítica ao modo como as disciplinas científicas são ensinadas na educação básica (também na universitária, embora haja mais espaço para o questionamento filosófico no ensino superior) e isso pode ter consequências interessantes para o ensino de filosofia no mesmo segmento da educação.

A intenção deste artigo é, a partir de duas constatações iniciais relativas ao ensino de ciências, tentar contribuir para o ensino de filosofia. Quais seriam as duas constatações? A primeira é a de que há algo fundamentalmente errado quando o ensino de ciências se dá por mera apresentação de um produto (uma ou algumas teorias, a mera exposição de explicações definitivas para um fenômeno, uma lei traduzida em fórmulas, equações, constantes, funções etc.) e treino em aplicar tal produto. Tal tipo de apresentação pouco 
faz em ensinar o processo do fazer científico, isto é, o professor adepto do ensino enquanto apresentação de um produto final não cuida de fazer o aluno pensar com curiosidade científica, criar hipóteses, justifica-las, testá-las, etc. A segunda constatação é que há algo de fundamentalmente errado quando professores de filosofia procuram reproduzir os erros do mau ensino de ciência.

Minha proposta, portanto, é a de fornecer subsídios para se pensar o ensino de filosofia a partir de questões análogas às que a filosofia lança sobre a ciência e seu ensino. Ao lançar luz sobre algumas questões filosóficas direcionadas à ciência ou motivadas por ela, não só o ensino de filosofia poderia se enriquecer com tal discussão, mas ajudado pela filosofia, também o ensino de ciências.

\section{Problema de demarcação}

Uma das questões mais fundamentais da filosofia da ciência é justamente a de traçar uma linha delimitando o que é ciência e o que não é ciência. Esse problema, chamado problema da demarcação, envolve discussões sobre a natureza do conhecimento científico, sua justificação lógica, seu alcance empírico e as regras para reconhecer um saber de tal tipo, poderiam ser sintetizados na tarefa de responder à simples pergunta: "o que é a ciência?". Ora, uma resposta do senso comum a essa pergunta seria igualmente simples: "ciência é todo conhecimento obtido mediante a aplicação do método científico". Isso nos levaria a uma nova questão: saber qual é o método científico que nos conduzirá a um conhecimento significativo. Segundo o filósofo Karl Popper (1902-1994), se existe uma resposta a essa pergunta, não pode ser a apresentação de uma lógica da descoberta, cujos caminhos são infinitamente variáveis. A lógica da pesquisa científica seria nada mais do que o procedimento lógico capaz de justificar a pertinência das conjecturas atualmente sustentadas pelos cientistas. Popper atribui aos filósofos iluministas David Hume e Immanuel Kant as primeiras tentativas de solução do problema da demarcação: 
Denomino problema de demarcação o problema de estabelecer um critério que nos habilite a distinguir entre as ciências empíricas, de uma parte, e a Matemática e a Lógica, bem como os sistemas "metafísicos", de outra. Este problema foi abordado por Hume, que tentou resolvê-lo. Com Kant, tornou-se o problema central da teoria do conhecimento. (POPPER, 2001, p. 35)

Não pretendo aqui mais do que enunciar o problema da demarcação. Há, entre filósofos da ciência, algumas respostas possíveis tanto por parte de verificacionistas, quanto do próprio Popper (que sugere o falsificacionismo) ou mesmo negativas de que haja uma entidade monolítica invariável chamada "A ciência", perspectiva defendida por Kuhn (2003) e Feyerabend (2007). Todas essas perspectivas, por sua vez, são problemáticas por razões que não interessam especialmente a este trabalho.

Mas qualquer professor de alguma disciplina científica, ao discutir minimamente sobre sua área de pesquisa e ensino, precisa ter uma definição pelo menos implícita do que seja a natureza da ciência que pretende discutir. Se há uma linha (ainda que tênue) que define o que é ciência e o que é filosofia, então também deve ser minimamente possível dizer os contrastes e as semelhanças que a filosofia guarda com a ciência. Ora isso é fundamental quando se ensina filosofia (e ciência), já que é só a partir dessa conceituação mínima que seria possível conduzir qualquer trabalho de ensino. Isto é, todo professor de filosofia tem alguma concepção de filosofia sem a qual seu trabalho não tem o menor sentido. Não se quer com isso dizer que conceituar filosofia seja uma tarefa simples ou não problemática. Ao contrário, é um problema filosófico análogo ao problema da demarcação. Mas tampouco é simples definir o que é ciência, do contrário não haveria tantas tentativas alternativas de solução ou dissolução desse problema. Se há alguma diferença fundamental entre definir o que é filosofia e definir o que é ciência é o fato de que a tentativa de definir ciência não é um problema científico. Não há meios de fazê-lo através de hipóteses testáveis ou por provas formais. Ao ensaiar uma resposta à pergunta "o que é ciência?", tal resposta se dá por meios filosóficos. O mesmo quando tentamos definir filosofia. É justamente isso que torna o ensino de filosofia uma questão filosófica. Pois o ensino parte de uma concepção (ainda que conscientemente defeituosa) de filosofia. Então o 
ensino de ciências e de filosofia se dá com alguma crença filosófica sobre o que é a disciplina lecionada e como ela é ou deve ser praticada.

Quando nos perguntamos pela natureza dos problemas filosóficos, podemos estabelecer pelo menos uma diferença entre a filosofia e as diversas ciências ${ }^{2}:$ os problemas científicos podem ser estudados por meio de teorias que por sua vez são sustentadas com base em provas formais (quando nos referimos a ciências formais como a matemática e a lógica), em observações controladas que corroboram ou falsificam tais teorias (no caso das ciências humanas e das ciências da natureza) e em raciocínio intenso. Para os filósofos, só o raciocínio intenso está disponível. Não podemos abordar os problemas filosóficos recorrendo a dados empíricos, isto é, seu tratamento é exclusivamente por meio de teorias que só podem ser justificadas com argumentos e não com observações controladas ou regularidade estatística. Entrevistar inúmeras pessoas não nos diz nada sobre a natureza da felicidade, não há estatísticas que provem a existência ou inexistência do livre-arbítrio ou de Deus, não existem fenômenos que corroboram nossas crenças morais ou epistemológicas e não existem provas matemático-formais ${ }^{3}$ de que juízos estéticos são objetivos ou subjetivos ou ainda de que a distribuição da riqueza deva ser feita conforme o merecimento ou equitativamente. Ao observarmos a história das ciências, entretanto, reconheceremos que vários problemas que hoje são estudados por ciências particulares eram filosóficos em sua origem. Isso é particularmente perceptível no estudo da história da física, da química, da biologia, da psicologia e da sociologia. Recentemente isso pode ser atestado nos avanços recentes da neurociência. Quando foi possível certo consenso metodológico de como tratar um problema específico, quando

\footnotetext{
2 Aqui quase sempre nos referiremos às ciências da natureza, embora o caráter empírico que ressaltamos também esteja presente em ciências sociais e humanas, por meio de correlações estatísticas, entrevistas, artefatos arqueológicos e fontes históricas.

3 A nossa menção a provas formais é importante para distinguir filosofia e as ciências formais como a lógica formal e a matemática. Tal como na filosofia, aquelas ciências não dependem de testes experimentais, mas diferentemente da filosofia, elas exibem teoremas e provas cuja verdade pode ser estabelecida com uns poucos postulados e axiomas. A filosofia está longe de possuir esse tipo de consenso axiomático e quando a tradição fala de "provas" em filosofia (tal como as provas sobre a existência de Deus), o termo assume um significado muito diferente do contexto das ciências formais. Esta é uma observação que também cabe, por exemplo, ao uso do termo "prova" no contexto jurídico, o qual está longe de ser um resultado de demonstrações formais, e muito mais próximo de um raciocínio explicativo do tipo inferência pela melhor explicação.

Revista Digital de Ensino de Filosofia - Santa Maria - vol.3. n.1 - jan./jun. 2017.
} 
estudiosos da área concordaram que uma teoria ou um grupo delas conseguia explicar e prever fenômenos, classificar e organizar o conhecimento deste ramo do conhecimento, tal campo específico de problemas passa a integrar uma nova ciência. Em muitos casos, uma ciência independente só existe porque deu por resolvidas certas questões filosóficas, isto é, assumindo alguma filosofia como premissa (por exemplo: o fisicalismo é uma das possíveis posturas metafísicas disponíveis, mas dado como certo em algumas ciências específicas, como na neurociência). Para Bertrand Russell, a filosofia lida com esse resíduo que não pode ainda ser tratado de modo científico e isso explicaria a suposta ausência de progresso filosófico, bem como o caráter em aberto dos problemas filosóficos:

\begin{abstract}
A filosofia, como todos os outros estudos, visa primariamente o conhecimento. O conhecimento que visa é o tipo de conhecimento que dá unidade e sistema ao corpo das ciências, e o tipo que resulta de um exame crítico dos fundamentos das nossas convicções, preconceitos e crenças. Mas não se pode defender que a filosofia tem tido um enorme sucesso nas suas tentativas de fornecer respostas definitivas para as suas questões. Se perguntarmos a um matemático, a um mineralogista, a um historiador ou a qualquer outro homem instruído que corpo definitivo de verdades foram estabelecidas pela sua ciência, a sua resposta irá durar tanto tempo quanto estivermos dispostos a ouvir. Mas se fizermos a mesma pergunta a um filósofo, ele irá ter de confessar, se for cândido, que o seu estudo não alcançou resultados positivos como os que foram alcançados pelas outras ciências. É verdade que isto se explica em parte pelo fato de que, mal o conhecimento definitivo sobre qualquer assunto se torna possível, tal assunto deixa de se chamar filosofia, e torna-se uma ciência independente. [...] Assim, em grande parte, a incerteza da filosofia é mais aparência do que realidade: aquelas questões que são já susceptíveis de respostas definitivas são colocadas nas ciências, ao passo que só permanecem para formar o resíduo a que se chama filosofia aquelas a que, atualmente, nenhuma resposta definitiva se pode dar. (RUSSELL, 2005, p. 120)
\end{abstract}

Quando tratamos do termo "ciência" podemos com isso referir tanto ao produto que a ciência ocidental apresenta quanto ao processo pelo qual os cientistas adquirem conhecimento. Na educação básica, sobretudo, o ensino de ciências naturais enfatiza o produto. Ele se dá de modo bastante dogmático, isto é, são apresentados basicamente os produtos da ciência em questão tais como as Leis de Newton, a lei de Kepler, a Lei de Coulomb, a Lei 
de Boyle etc. Tais leis são traduzidas em fórmulas e os estudantes precisam fazer exercícios onde aplicam o saber transmitido sem ter a oportunidade de entender o modo como os cientistas chegaram àquelas formulações. Quando os professores recorrem à história da ciência, quase sempre o fazem apresentando ligeiramente uma coleção anedótica de teorias mais ou menos absurdas que continham alguma verdade na medida em que contribuíram para que se chegasse às teorias paradigmáticas da ciência de hoje. Nas palavras do historiador da ciência Thomas Kuhn,

É característica dos manuais científicos conterem apenas um pouco de história, seja um capítulo introdutório, seja, como acontece mais frequentemente, em referências dispersas aos grandes heróis de uma época anterior. Através dessas referências, tanto os estudantes como os profissionais sentem-se participando de uma longa tradição histórica. Contudo, a tradição derivada dos manuais, da qual os cientistas sentem-se participantes, jamais existiu. Por razões ao mesmo tempo óbvias e muito funcionais, os manuais científicos (e muitas das antigas histórias da ciência) referem-se somente àquelas partes do trabalho de antigos cientistas que podem facilmente chegar a ser consideradas como contribuições ao enunciado e à solução dos problemas apresentados pelo paradigma dos manuais. (KUHN, 2003, p.177).

Tal ensino descuidado de história da ciência não só parece falsear a dimensão do trabalho de cientistas do passado, como também deixa parecer que a ciência é uma atividade dogmática. Uso aqui o termo "dogmático" em oposição a "crítico", isto é, sem exame criterioso. Assim, muitos professores de ciências fazem parecer que não há ampla discussão crítica sobre a pertinência dos métodos e dos resultados científicos obtidos, não mostram as alternativas teóricas às teorias que são ensinadas como verdadeiras para os alunos. Não expõem os casos limites das teorias ensinadas e de que modo várias teorias não mais consideradas eram capazes de fazer boas previsões e dar boas explicações. Os alunos, muitas vezes, não são instigados a pensar hipóteses para problemas científicos nem a testar tais hipóteses. Eles são, ao contrário, incentivados a apenas memorizar fórmulas e reproduzir as explicações para os fenômenos estudados a partir das teorias lecionadas em sala de aula sem que se perceba a natureza crítica da ciência, os problemas com que os cientistas precisam de fato lidar em sua pesquisa. Em muitos casos o aprendizado se dá sem um único laboratório disponível. Tudo isso contribui Revista Digital de Ensino de Filosofia - Santa Maria - vol.3. n. 1 - jan./jun. 2017. 
para que jovens e adolescentes não compreendam como se faz ciência e apenas reproduzam resultados prontos oferecidos como "verdades sobre o mundo". As ciências também possuem seus casos limites, suas questões de fronteira, tal como a filosofia. Vírus são seres vivos? Elétrons são ondas ou nuvens? Essas e outras questões mostram que as fronteiras entre filosofia e ciência não estão absoluta e definitivamente traçadas. Mas ao contrário da filosofia, que guarda uma relação bastante estreita com sua história, muitas ciências tendem a relativizar o valor do conhecimento de sua própria história, como se isso não mostrasse um pouco a natureza do que fazem os pesquisadores dedicados a tal ciência.

Meu parecer é o de que o ensino de ciências se enriqueceria bastante se recorresse com mais frequência e de modo sério à história e à filosofia da ciência. Por outro lado, professores de filosofia, sobretudo no ensino médio, possuem a tentação de reproduzir a metodologia desse ensino enrijecido de ciências: no lugar de enfatizar o processo, enfatizam o produto. Em parte, isso se explica pelo fato de que há uma tradição bastante consolidada de ensino de ciências no Brasil, ao passo que o ensino de filosofia foi reintroduzido obrigatoriamente a partir de 2008 na educação básica (e sofre o risco de ser novamente retirada com a MP 746). Ao retornar para as escolas de ensino médio, a filosofia encontra uma estrutura institucional adaptada à transmissão de conteúdos. Desde a disposição da sala de aula, passando pelas atividades obrigatórias de avaliação (como semana de provas com formato predefinido), o professor de filosofia precisa adequar seu ensino ao modelo preexistente. É um modelo baseado no ensino de produtos científicos e não de processo. Nada mais justificável do que olhar para o modo como procedem os professores de física, química, história e geografia e tentar fazer algo parecido. O problema é que só há um produto gerado pela prática filosófica: a história da filosofia. No modelo de educação que a instituição escolar parece favorecer lecionar história da filosofia como uma série de conteúdos que o aluno precisa saber para a prova ou simulado de questões objetivas é uma atitude bastante ajustada. A história da filosofia pode ser ocasião de contato dos alunos com a prática filosófica ou apenas mais uma série de conteúdos para memorizar. É preciso veementemente evitar que o ensino de Revista Digital de Ensino de Filosofia - Santa Maria - vol.3. n. 1 - jan./jun. 2017. 
filosofia se torne somente o segundo caso. Trata-se de uma condição para um bom ensino de filosofia, afinal, como podemos afirmar que a filosofia é uma disciplina crítica, argumentativa, questionadora, temida pelos regimes autoritários e capaz de proporcionar uma experiência de racionalidade refinada e profunda a nossos estudantes se tudo que lhes é permitido limita-se a reproduzir com suas próprias palavras o que determinado filósofo pensava sobre determinado assunto? Quando tudo o que um aluno pode almejar é saber o que Platão entendia por realidade, ou o que Descartes sugere ser o ponto arquimediano do conhecimento, ou ainda como Kant conceituava $O$ esclarecimento, somente por sorte esse ou essa estudante poderia se tornar um(a) pensador(a) mais crítico(a), capaz de autonomia intelectual. Na verdade, isso pode ser extremamente decepcionante, assim como estudar química sem laboratório, sem fazer na prática o que químicos fazem. É preciso que os estudantes entrem em contato com o fazer filosofia, que o professor filosofe com eles em sala. E somente com alguma definição mínima de filosofia o professor poderia pratica-la com seus alunos.

Mas como fazer isso? Não há resposta simples para essa questão, mas entendo que a filosofia da ciência também tenha algo a dizer sobre isso. Refiro-me ao problema do método, o qual, por sua vez se desdobra numa decisão entre o método ser um conjunto de regras para descobrir ou para justificar hipóteses.

\section{Problema de demarcação}

Como já dissemos, tentar definir o que seja a ciência resvala numa questão também fundamental da filosofia da ciência: o problema do método. Qual o método que distingue o processo de obtenção de crenças científicas em oposição a outros tipos de crenças, por exemplo, da religião, do senso comum e da superstição? Existe uma lógica por trás da pesquisa científica? Como o saber científico procura justificar-se? Essas questões epistemológicas produziram uma discussão bastante fértil envolvendo cientistas e filósofos. Desde Bacon viemos tentando estabelecer quais os passos necessários para 
que uma afirmação não seja feita por mera convenção social ou por mera convicção pessoal.

Mas também nesse campo há certas controvérsias que vale a pena enfatizar: o chamado método científico seria constituído de uma série de regras para descobrir (ou inventar, dependendo da perspectiva) ou seria um conjunto de regras para justificar as proposições da ciência? Muitos filósofos da ciência, ainda que concordem que certos princípios heurísticos sejam importantes para possibilitar a descoberta ou invenção de hipóteses relevantes ${ }^{4}$, entendem que o método científico é, sobretudo, um método de justificação do saber científico. Ao responder à pergunta "Como é que você sabe que as coisas são assim?", o cientista não mostra como foi seu processo de criação da hipótese ou da coleção de hipóteses que compõem sua teoria, mas como suas hipóteses são confirmadas por experimentos, como elas fazem previsões acertadas, como elas são coerentes entre si e com outras leis científicas, como elas tornam familiar certos processos e fenômenos antes desconhecidos. Essa perspectiva diferencia dois contextos distintos no procedimento científico: o contexto da descoberta e o contexto da justificação. Veja-se, por exemplo, o que diz Hempel sobre essa diferença:

\begin{abstract}
A transição dos dados à teoria requer uma imaginação criadora. As hipóteses e teorias científicas não são derivadas dos fatos observados, mas inventadas com o fim de explicá-los. [...] No seu esforço para achar uma solução ao seu problema, o cientista pode soltar as rédeas de sua imaginação e o rumo do seu pensamento criador pode ser influenciado até por noções cientificamente discutíveis. Ao estudar o movimento planetário, por exemplo, Kepler foi inspirado por seu interesse numa doutrina mística sobre números e por um apaixonado desejo de demonstrar a música das esferas. Nada disso impede que a objetividade científica fique salvaguardada, Pois as hipóteses e as teorias que podem ser livremente inventadas e livremente propostas não podem ser aceitas se não passarem escrutínio crítico, especialmente pela verificação das implicações capazes de serem observadas ou experimentadas. (HEMPEL, 1974, pp.27-29 grifos do autor).
\end{abstract}

\footnotetext{
${ }^{4}$ Por exemplo: recorrer a hipóteses consistentes com o atual estado do conhecimento, preferir as explicações mais simples que cubram o maior número de fenômenos possíveis, estabelecer analogias entre fenômenos diferentes para ver se é possível enquadrar o fenômeno estudado em alguma lei já conhecida, ater-se a hipóteses que façam previsões e não apenas acomodem os fenômenos etc.

Revista Digital de Ensino de Filosofia - Santa Maria - vol.3. n. 1 - jan. jun. 2017.
} 
Em outras palavras, a criação de hipóteses depende de imaginação criativa, elementos irracionais e intuições, ao passo que o que torna as proposições das ciências justificadas (em linguagem mais rigorosa, candidatas a conhecimento) é a existência do escrutínio crítico tipificado pelos testes empíricos que podem ser conduzidos pelos pares. Embora também essa divisão não deva ser absolutizada5, uma vez que a prática científica envolve tanto o procedimento criativo quanto o mecanismo justificatório e ambos podem ocorrer simultaneamente, ela pode ajudar o professor de filosofia a distinguir os elementos puramente contextuais daquelas razões que sustentam (ou sustentaram) uma teoria filosófica. Anteriormente eu me referi a dois tipos de ensino de história da filosofia, um voltado para a mera exposição de conteúdos e outro no qual o aluno tem contato com o processo do filosofar a partir do modo como os filósofos o fizeram na história. Parece-me que uma história da filosofia que apenas procura mostrar como um pensador refletia em consonância com sua época, a partir de uma influência, de que modo sua teoria amadureceu e chegou a ser formulada é um equivalente a concentrar apenas no contexto da descoberta. Coisa um pouco diferente é mostrar os argumentos que sustentam a filosofia de um pensador e mesmo criticá-los. Anthony Kenny, autor de variadas obras dedicadas à história da filosofia, faz uma distinção similar. Para ele a filosofia histórica e a história das ideias não são a mesma coisa, constituídas de objetivos diversos:

De modo típico, a filosofia histórica busca as razões, ou a justificação, por trás das afirmações feitas no texto sob escrutínio. Quanto ao outro objetivo, a história das ideias, a meta não é chegar à verdade sobre a matéria em discussão, mas alcançar o entendimento sobre uma pessoa, sobre uma época ou sobre uma sucessão histórica. O historiador das ideias, tipicamente, investiga não tanto as razões quanto as fontes, as causas ou os motivos para que tenha sido dito o que foi dito no texto abordado. (KENNY, 2011, pp. 21-22)

Tal distinção não é feita para qualificar uma abordagem e desqualificar a outra. Kenny adverte sobre a necessidade de ambas para que o estudo da história da filosofia não cometa o pecado da superficialidade nem do

\footnotetext{
${ }^{5} \mathrm{Na}$ visão de Feyerabend, por exemplo, fazer tal distinção entre dois contextos (da descoberta e da justificação) equivale a separar dois elementos intrinsecamente misturados por meio de decreto. (cf. FEYERABEND, 2007 p. 207ss). Uma reconstrução do argumento de Feyerabend contra a mencionada distinção pode ser consultada em meU AUTOR, Data, p.

Revista Digital de Ensino de Filosofia - Santa Maria - vol.3. n.1 - jan./jun. 2017.
} 
anacronismo. A tentação da superficialidade seria dada por historiadores da filosofia que não estão inteirados dos problemas filosóficos tratados pelos autores estudados ao passo que o erro de anacronismo tem a ver com a falta de conhecimento do contexto em que o texto estudado se insere. O que chamo aqui a atenção é para o fato que muitas vezes estamos lecionando a parte mais propriamente contextual sem cuidar tanto em proporcionar a experiência de avaliar criticamente os argumentos apresentados.

Se olharmos para o próprio contexto em que a filosofia está inserida no âmbito do Ensino Médio, não estamos lidando com alunos que escolheram a filosofia ou que pretendem seguir carreira acadêmica na área. Estamos lidando com estudantes que antes de saber o que é e como se faz filosofia, precisam fazer provas sobre como as condições históricas do mundo grego foram essenciais para o surgimento da filosofia ou como a revolução científica influenciou o trabalho de Descartes. São questões muito importantes e interessantes para o apaixonado por filosofia. Mas seria a melhor maneira de fazer um adolescente ter seu primeiro contato com a disciplina? Talvez cuidar para que o aluno entenda os problemas que motivaram tal ou tal texto filosófico, bem como a discussão crítica dos argumentos que sustentam essa ou aquela teoria filosófica possa fazer mais sentido ao aluno do ensino médio. A vantagem desse tipo de tratamento por problemas é que o estudante compreende que está estudando este ou aquele pensador não simplesmente porque ele é de uma determinada época ou porque ele nasceu depois daquele outro. $O$ enfoque na justificação põe o aluno no meio do processo de filosofar, entender as razões, avaliar se são boas ou não, contrastar com outras teorias que visam responder os mesmos problemas.

A analogia com o ensino de ciências volta a nos dizer algo interessante aqui. O professor de física que não mostra o caráter problemático de uma teoria, bem como o fato de que existem alternativas teóricas àquela perspectiva, favorece a ideia de que ali está sendo ensinada uma verdade definitiva. Nada mais distante da realidade científica que, à semelhança da filosofia, possui uma história de iniciar-se com problemas e alimentar-se deles. O aluno, por sua vez, que se acostumou a esse tipo de ensino em ciências Revista Digital de Ensino de Filosofia - Santa Maria - vol.3. n. 1 - jan./jun. 2017. 
pode criar uma falsa expectativa quando se depara com a filosofia pela primeira vez. Trata-se do que Kant já havia denunciado em texto amplamente difundido sobre aprender filosofia e aprender a filosofar. $O$ filósofo mesmo explica a vantagem de enfatizar o processo e não o produto do conhecimento:

Espera-se que o professor desenvolva no seu aluno, em primeiro lugar, o homem de entendimento, depois, o homem de razão, e, finalmente, o homem de instrução. Este procedimento tem esta vantagem: mesmo que, como acontece habitualmente, 0 aluno nunca alcance a fase final, terá mesmo assim beneficiado da sua aprendizagem. Terá adquirido experiência e ter-se-á tornado mais inteligente, se não para a escola, pelo menos para a vida. Se invertermos este método, o aluno imita uma espécie de razão, ainda antes de o seu entendimento se ter desenvolvido. Terá uma ciência emprestada que usa não como algo que, por assim dizer, cresceu nele, mas como algo que the foi dependurado. (KANT In: WALFORD \& MERBORT, 1992, pp. 2:306-7)

O próprio Kant cuida para que não entendamos sua afirmação como um simples dilema entre conteúdo e forma, produto e processo. Mas ele adverte que ao estudar um autor na história da filosofia não devemos fazê-lo como quem absorve passivamente um conteúdo pronto, mas como quem possui uma razão autônoma, capaz de julgar (por meio do instrumental metodológico fornecido neste próprio estudo) os méritos das teorias estudadas:

Por exemplo, o autor sobre o qual baseamos a nossa instrução não deve ser considerado o paradigma do juízo. Ao invés, deve ser encarado como uma ocasião para cada um de nós formar um juízo sobre ele, e até mesmo, na verdade, contra ele. $O$ que o aluno realmente procura é proficiência no método de reflectir e fazer inferências por si. E só essa proficiência lhe pode ser útil. Quanto ao conhecimento positivo que ele poderá talvez vir a adquirir ao mesmo tempo - isso terá de ser considerado uma consequência acidental. Para que a colheita de tal conhecimento seja abundante, basta que $O$ aluno semeie em si as fecundas raízes deste método. (KANT In: WALFORD \& MERBORT, 1992, pp. 2:306-7)

Ensinar uma teoria ao mesmo tempo em que se discute se os argumentos a favor da mesma são válidos e têm premissas plausíveis, se há contraexemplos relevantes a ela, se ela cria mais problemas do que resolve; tudo isso faz o aluno compreender intuitivamente o caráter crítico e reflexivo Revista Digital de Ensino de Filosofia - Santa Maria - vol.3. n.1 - jan./jun. 2017. 
da filosofia, sua busca pela verdade, a necessidade de justificação racional. Quando isso é feito, não se torna necessário "encerrar" uma discussão. Tal como já mencionamos na citação de Russell, a filosofia alimenta-se dessas questões para as quais não há tanto consenso quanto nas ciências. Introduzir, portanto, certas questões fundamentais da filosofia, bem como diferentes tentativas de respostas a elas e incentivar os alunos a pensar sobre elas é um modo de apresentar a filosofia como mais do que o mero repositório de conteúdos. As respostas que a história da filosofia apresenta a essas questões fundamentais também devem ser avaliadas e problematizadas, o que parece um caminho possível para os alunos entenderem a coerência entre as definições de filosofia dadas nas primeiras aulas e o estudo de certos textos filosóficos ao longo do ensino médio. Afinal, por meio desse processo, os estudantes podem ver "ao vivo" a filosofia sendo feita através de seus professores e com eles, através dos debates com o professor e com os colegas, na mais genuína tradição dialógica introduzida por Sócrates. Este caminho pode, inclusive, permitir ao aluno concordar ou discordar das perspectivas estudadas, já que elas não seriam a palavra final no assunto.

O texto de Kant já referido também pode ser lido como um diferencial entre a Filosofia e as Ciências empíricas, já que não há um livro onde podemos dizer: "ali está a filosofia", como muitas vezes se faz com a química, a física ou a biologia. Mas eu penso que tal crítica na verdade pode ser aprofundada no sentido de inverter o esquema denunciado no início deste artigo. Ao invés de copiar este ensino dogmático de ciências, o ensino de filosofia poderia favorecer uma mudança no modo como as ciências são ensinadas. Um ensino mais filosófico das ciências abriria alguns caminhos interessantes para o estudante, que entenderia melhor os mecanismos falíveis de justificação das teorias científicas e o caráter problemático, histórico e mutável das mesmas.

\section{Concluindo: Problema do método}

Obviamente as questões levantadas anteriormente dependem de outra problemática mais técnica e também diretamente correspondente a uma questão de filosofia da ciência: qual é o método da filosofia? Não há resposta 
simples a essa questão e podemos até pensar em vários métodos no lugar de um só. Traduzindo para o contexto do ensino de filosofia, talvez uma pergunta melhor fosse: Existe um método filosófico? Essa segunda pergunta tem uma resposta afirmativa, de vários métodos que podemos atestar ao longo da história da filosofia: o método dialógico (próprio dos diálogos de Platão, mas também presente em Galileu, Agostinho etc), o hermenêutico, o método fenomenológico-existencial, o método analítico-linguístico, o método genealógico são alguns exemplos. Não temos aqui espaço suficiente para elucidar cada um deles, mas podemos afirmar que mesmo estes métodos são de um modo ou de outro justificados com base em algumas razões. Dado o caráter argumentativo da filosofia, parece-nos apropriado lecionar o básico de lógica proposicional e de lógica informal para potencializar a avaliação de argumentos e de teorias filosóficas, bem como para possibilitar ao estudante que ele tenha recursos para pensar autonomamente com rigor. No mais, é importante que o professor se empenhe a praticar quaisquer que sejam os métodos identificados por ele como próprios do processo filosófico. É importante que o aluno incorpore esse processo e se habitue a. Na medida em que o processo e não o produto for enfatizado, os estudantes poderão entender o que parece tão abstrato naquela primeira aula em que o professor anuncia a nova matéria a ser estudada, uma coisa chamada "filosofia". É possível que no lugar de falar sobre filosofia, a prática do fazer filosofia, do apresentar problemas filosóficos e problematizar as soluções apresentadas na história da filosofia tornem muito mais compreensível a natureza dessa disciplina para quem não sabe o que ela éb.

\footnotetext{
6 Há ainda alguns problemas de filosofia da ciência que poderiam ajudar a refletir sobre a própria natureza da atividade filosófica, como a questão do progresso científico e seu análogo na filosofia e a questão se a meta de buscar a verdade é alcançável no nível científico e no filosófico (uma questão interna ao debate entre realismo e antirrealismo científico). São problemas que pretendo abordar numa continuação deste artigo. Por hora, é suficiente que o problema da demarcação e do método tenham motivado a repensar o ensino, tornando-o mais filosófico quer a disciplina lecionada seja alguma ciência, quer seja a própria filosofia.
} 


\section{Referências}

FEYERABEND, Paul. Contra o método. Trad. Cézar A. Mortari. São Paulo: Unesp, 2007.

HEMPEL, Carl, G. Filosofia da ciência natural. Trad. Plínio Sussekind, 2a . Edição. Rio de Janeiro: Zahar, 1974.

KANT, Immanuel. Anúncio do programa de inverno de 1765-1766. In: Theoretical Philosophy, 1755-1770 (edição de David Walford e Ralf Merbote, Cambridge University Press, 1992), pp. 2:306-7. Tradução de Desidério Murcho disponível no site: <http://criticanarede.com/fil_ensinarpensar.html>.

KENNY, Anthony. Uma nova história da filosofia ocidental. Vol. 1. Trad. Carlos Alberto Bárbaro. São Paulo: Loyola, 2011.

KUHN, Thomas. A estrutura das revoluções científicas. Trad. Beatriz Vianna Boeira e Nelson Boeira. São Paulo: Perspectiva, 2003.

POPPER, Karl. A lógica da pesquisa científica. Trad. Leônidas Hegenberg e Octanny Silveira da Mota. 9a. Edição. São Paulo: Cultrix, 2001.

RUSSELL, Bertrand. Os problemas da filosofia. Trad. Jaimir Conte. Florianópolis, 2005. Texto disponível online em: <http://conte.prof.ufsc.br/txt-russell.pdf>. 